\title{
Giant Antrochoanal Polyp: Anaesthetic Considerations
}

\author{
Ranu Surana ${ }^{I^{*}}$, Avnish Bharadwaj ${ }^{2}$ \\ ${ }^{1}$ Resident, ${ }^{2}$ Senior Professor, Department of Anaesthesia, Mahatma Gandhi Medical College and \\ Hospital, Jaipur, India
}

\begin{abstract}
Antrochoanal polyps (ACP) are benign lesions that arise from the mucosa of the maxillary sinus. Large antrochoanal polyps may extend in to the nasopharynx and beyond hyoid bone and reach almost up to the epiglottis. We present our experience of airway management for FESS in an 11-year child with a giant atypical antrochoanal polyp extending in to the oral cavity.
\end{abstract}

Keywords: antrochoanal polyp, FESS, difficult intubation, nasopharynx mass, difficult Airway

\section{Introduction}

Antrochoanal polyps represent 4-6\% of all nasal polyps. Chronic sinusitis and allergy are believed to be the possible aetiological factors. Unilateral nasal obstruction is the most common symptom. Surgical treatment of ACP should aim at total removal of all ACP components as incomplete removal results in recurrence. Anaesthetic management of patients with large antrochoanal polyps needs anticipation and adequate preparation for the associated problems.

\section{Case report}

A 11-year old girl presented with dysphagia \& change in voice of 12-month duration along with nasal obstruction \& foul-smelling nasal discharge. Patient noticed a mass protruding into the mouth with normal hearing with no complaints of repeated sneezing or disturbed sleep. Nasal examination revealed a mass occupying the entire left nasal cavity with pushing of the nasal septum to the contralateral

*Correspondence: Ranu Surana

E mail: drranumail@gmail.com

iD https://orcid.org/0000-0002-7084-7835

Received: 03/08/2020

Accepted: $26 / 10 / 2020$

DOI: http:/doi.org/10.4038/slja.v29i1.8654

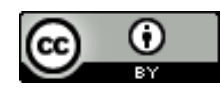

side. Oral examination revealed a growth protruding over the tongue in the oral cavity. The distal part of the growth had become thick and parched with foul smelling discharge and occasional bleeding spots. The mass could be seen on oral examination (Modified Mallampati grade 3 ).

CT Scan of paranasal sinuses revealed a large soft tissue density lesion in left maxillary sinus extending from the ostia to posterior nasal cavity and choana with posterior extension beyond the base of the tongue in to the oral cavity.

Contralateral extension in to right choana with partial obstruction along with bowing of nasal septum towards right side was present [Figures $1,2]$.

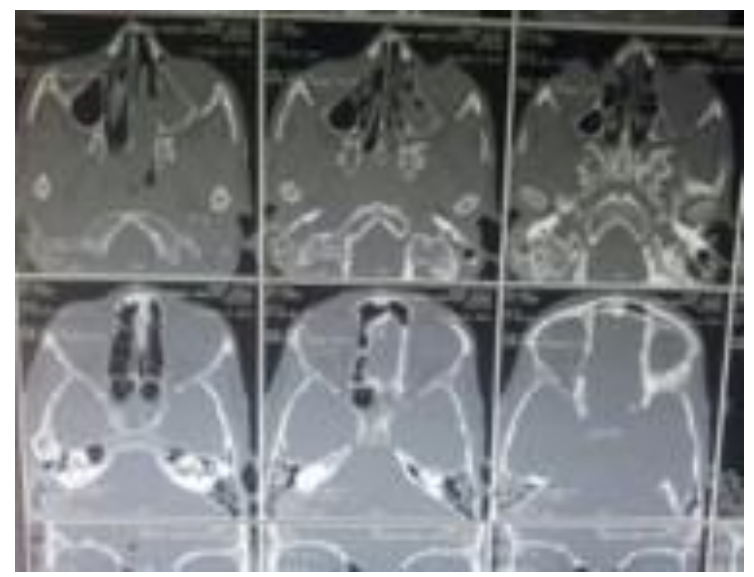

Figure 1

CT scan showing large antrochoanal polyp in left maxillary sinus 


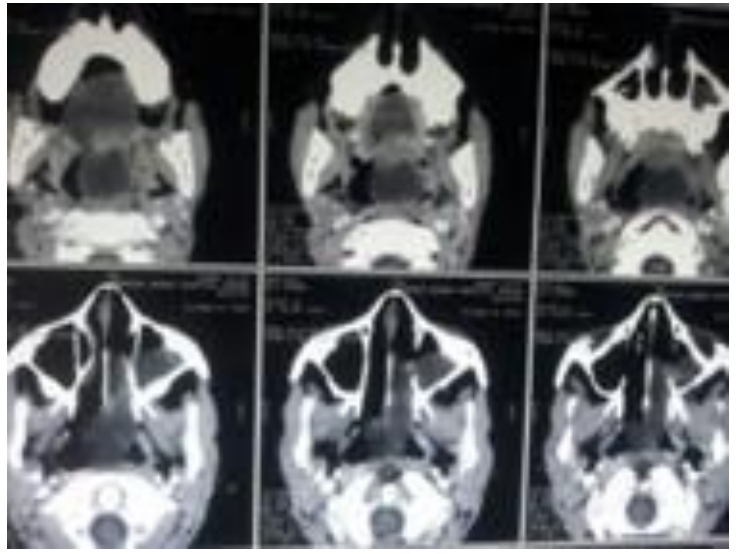

Figure 2

CT scan showing extent of the polyp

Due to its large size causing airway obstruction and the age of the patient, it was decided to perform the removal by FESS under general anesthesia. The observations in pre anaesthetic examination along with perusal of patient's records and CT Scan pictures pointed towards a possible difficult airway and difficult intubation.

Flexible Fiberoptic bronchoscope was kept standby and surgeon was asked to be prepared for surgical emergency access. Before starting general anesthesia, preoxygenation for 3 minutes was done. Glycopyrrolate $0.1 \mathrm{mg}$ and Ondansetron $4 \mathrm{mg}$ IV was given. Sedative premedication was not administered. Induction of anesthesia was done with Propofol $2.0 \mathrm{mg} /$ $\mathrm{Kg}$ administered slowly 90 seconds following the intravenous injection of $1 \mathrm{mg} / \mathrm{kg}$ lignocaine. Preserving spontaneous respiration, a check direct laryngoscopy was done with Macintosh laryngoscope to examine the access available for airway management which revealed a Cormack Lehane Gr III view. However, it was decided to proceed since mask ventilation was possible. Suxamethonium $1.0 \mathrm{mg} / \mathrm{kg}$ was administered and IPPV with $100 \%$ oxygen was done. A careful laryngoscopy was performed while pushing aside the mass. Now the view was Cormack - Lehane Gr II; intubation of trachea could be accomplished with a $6.0 \mathrm{~mm}$ cuffed tracheal tube. Further maintenance of anesthesia was done with Sevoflurane in nitrous oxide and oxygen on controlled ventilation with atracurium [Figures 3,4].

The polyp was excised using zero-degree nasal endoscopy by oral route in toto. The polyp

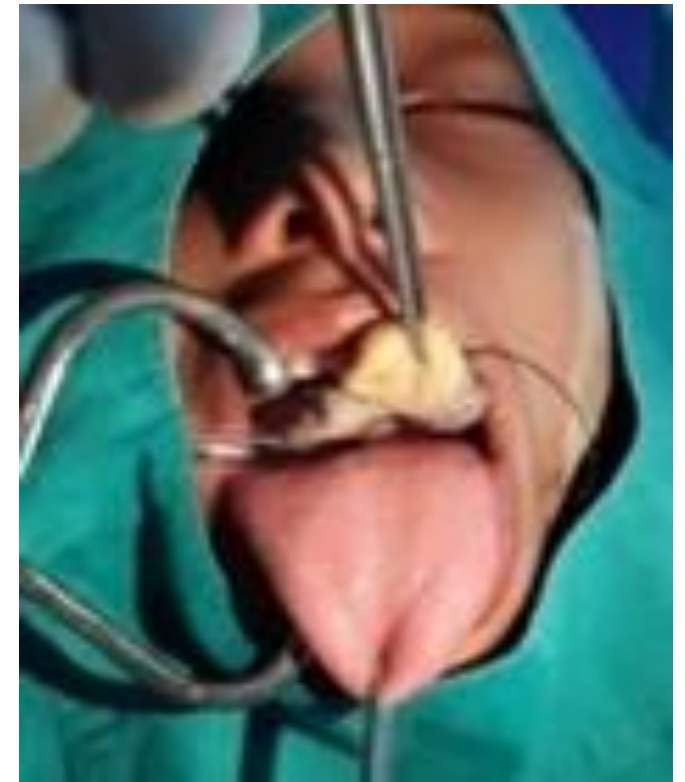

\section{Figure 3}

Protrusion of the antrochoanal polyp from the oral cavity.

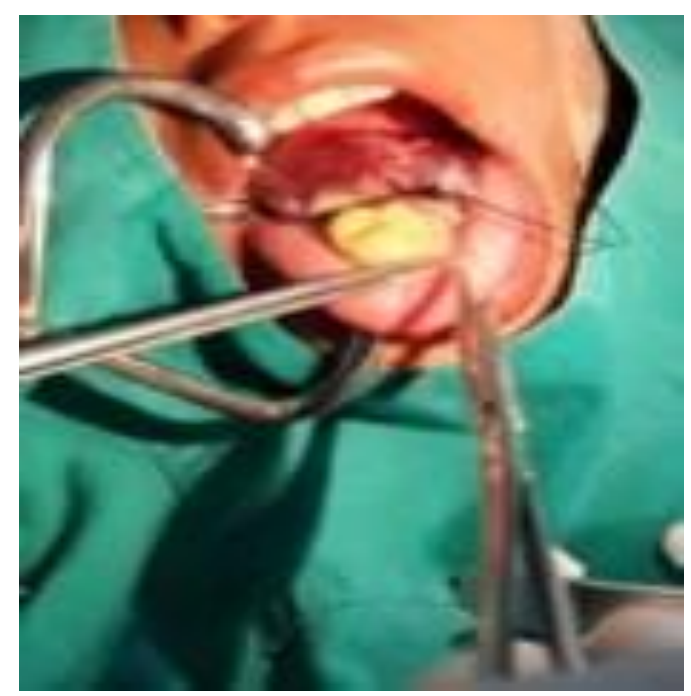

\section{Figure 4}

Growth pushed aside using a suture to improve field of view

was $15 \mathrm{~cm}$ in length as seen in Figure 5. The oral part of the polyp showed metaplastic changes towards the distal end and which was friable, however due to careful laryngoscopy there was no bleeding during airway management. Extubation was done on return of protective reflexes after careful removal of oropharyngeal packs and laryngoscopic suction under direct vision and removal of secretions and blood clots. The post-operative period was uneventful. 


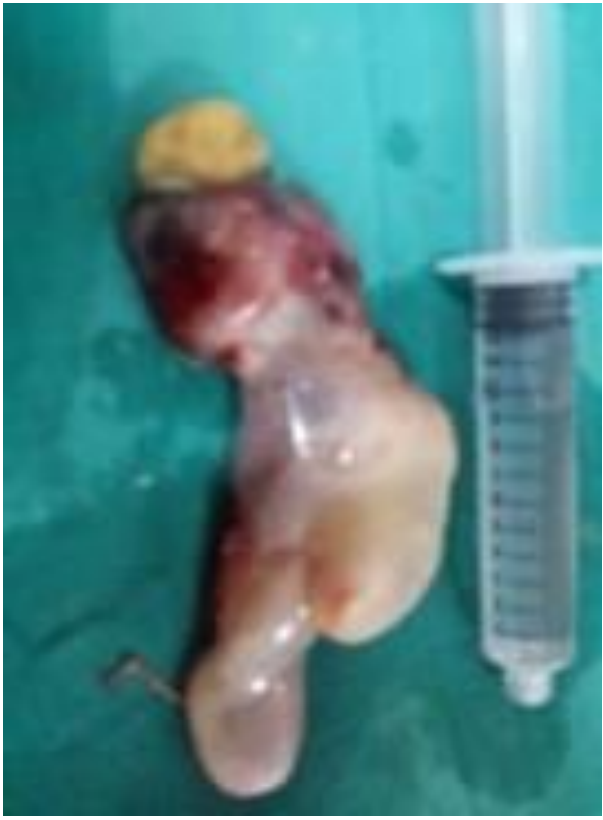

Figure 5

$15 \mathrm{~cm}$ large antrochoanal polyp delivered in toto.

\section{Discussion}

ACPs are benign lesions arising from the mucosa of the maxillary sinus. Nasal obstruction is the main symptom. Obstructive sleep apnea has also been reported as a symptom. ${ }^{1}$ The increased size and weight of the mass can cause its auto amputation thereby causing stridor which can be fatal. ${ }^{2,3}$ Our patient had an uncommon presentation of antrochoanal polyp i.e. change in voice and dysphagia. Thorough preoperative evaluation of the airway including indirect laryngoscopy to see the post-nasal space and larynx for any growth and CT paranasal sinuses to see the extent of the mass is a necessary prerequisite.

The definitive treatment of ACP is surgical removal. Caldwell-Luc procedure, polypectomy and FESS is performed for ACP treatment. In a case series by Qaisar et al, antrochoanal polypectomy by FESS was performed in $91 \%$ patients, while Caldwell Luc operation was performed in $9 \%$ cases, mainly for recurrent ACP. ${ }^{4}$ In our case, there was complete obstruction of nasal cavity along with bowing of nasal septum of the contralateral side obscuring the laryngeal view for the anesthesiologist. Anesthetic challenges were possible difficult ventilation and difficult intubation with complete nasal obstruction. Risk of bleeding from the injury to the polyp was high, particularly from the metaplastic part while attempting laryngoscopy and intubation. FESS needs a bloodless field for microsurgery requiring precise circulatory manipulations. Flexible fiberoptic bronchoscope and equipment for emergency cricothyroidotomy and jet ventilation were available for any anticipated difficulty.

There was no increase in the degree of obstruction after the patient assumed supine position while still conscious. Loss of muscle tone and airway collapse after muscle relaxant administration increase the vulnerability of the upper airway to become obstructed. However, there was no difficulty in mask ventilation so we went ahead with administering the relaxant. Anesthesia was induced with propofol and sevoflurane, preserving the spontaneous respiration. Finally, while attempting intubation, the growth was pushed aside, aided by placing preoperative suture thread through it. With this plan, we could perform tracheal intubation without much difficulty. We did not require use of oropharyngeal airway for airway management, contrary to a case report by Bhatia et al. ${ }^{5}$ Similar approach has been described by Chakravarty et al. ${ }^{6}$ Occasionally, Macintosh laryngoscopy may reveal only epiglottis (Cormack-Lehane grade 3) and Yoko Hori et al have used a video laryngoscope for successful intubation in such a case. ${ }^{7}$ Because of the risk of aspiration of blood, extubation should be performed after the return of protective reflexes.

\section{Conclusion}

This case illustrates that with good planning, successful anesthetic management of such large antrochoanal polyps can be performed. X-ray neck and CT scan are helpful and are recommended for optimum anesthetic management in patients presenting with nasopharyngeal mass.

\section{References}

1. Venkatachalam VP, Gupta N, Suri JC, Gandotra SC. Antrochoanal polyp-a cause of obstructive sleep apnoea in children. Indian J Otolaryngol Head Neck Surg. 1998; 50 (1): 92-4. https://doi.org/10.1007/bf02996787 PMID: 23119391

2. Kolwadhkar BP, Ankale NR, Bagewadi SB, Patil RN. Unusual Presentation of an Antrochoanal polyp. Bombay Hospital Journal. 2005; 47 (1): 82-83. https://doi.org/10.11604/pamj.2017.26.233.12054 
3. Shashinder S, Kuljit S, Suhba ST, Arumainathan UD, Gopala KG.Intermittent respiratory obstruction secondary to an antrochoanal polyp: a rare late presentation. Med J Malaysia. 2007; 62 (1): 72-3.

$\underline{\text { https://doi.org/10.7860/jcdr/2017/23639.9285 }}$

PMID: 17682578

4. Qaisar Khan, Fazal-I-Wahid, Asgharullah Khan. Antrochoanal polyps: presentation and management. Khyber Journal Medical Sciences. 2013; 6 (2): 256-9.

https://doi.org/10.13188/2380-0569.1000026

5. Prakash R, Bhatia VK. Anaesthetic management of a large atypical antrochoanal polyp for FESS. Int J Sci Res. 2013; 2: 90-1.

https://doi.org/10.5832/a3824
6. Chakravarty N, Shende S, Dave SP, Shidhaye RV. Airway management in a patient with large antrochoanal polyp. Anaesth Pain \& Intensive Care. 2014; 18 (2): 198-200.

https://www.apicareonline.com/index.php/APIC/ article/view/401/1329

7. Yoko Hori, Kana Taniguchi, Tadashi Okabe, Atsuhiro Sakamoto. A case of unexpectedly difficult intubation caused by a large asymptomatic choanal polyp. JA Clinical Reports. 2016; 2: 2.

https://doi.org/10.1186/s40981-016-0028-7 